\title{
A Brief Depression and Anxiety Rating Scale for Sexual Violence Victims
}

\author{
Soohyun Chae',2, Jiyoon Shin ${ }^{1,2}$, Dajung Ji', Jae-Won Choi ${ }^{3}$, Ju-Yeon Lee ${ }^{4}$, Minha Hong ${ }^{5}$, Tae-Won Park ${ }^{6}$, \\ Kyoung Min Kim ${ }^{7}$, Sunhwa Lee ${ }^{8}$, Soo Yeon Kim ${ }^{9}$, Kihyun $\mathrm{Kim}^{10}$, and Jae-Won Kim ${ }^{1,2} \bowtie$ \\ ${ }^{1}$ Division of Child and Adolescent Psychiatry, Department of Psychiatry \& Behavioral Sciences, Seoul National University College of Medicine, \\ Seoul, Republic of Korea \\ ${ }^{2}$ Department of Psychiatry, Seoul National University Hospital, Seoul, Republic of Korea \\ ${ }^{3}$ Department of Psychiatry, Gyeongsang National University Hospital, Jinju, Republic of Korea \\ ${ }^{4}$ Department of Psychiatry, Chonnam National University Medical School, Gwangju, Republic of Korea \\ ${ }^{5}$ Department of Psychiatry, Myongji Hospital, Hanyang University College of Medicine, Goyang, Republic of Korea \\ ${ }^{6}$ Department of Psychiatry, Chonbuk National University Hospital, Jeonju, Republic of Korea \\ ${ }^{7}$ Department of Psychiatry, College of Medicine, Dankook University, Cheonan, Republic of Korea \\ ${ }^{8}$ Sunflower Center of Chungnam for Women and Children Victims of Violence, Cheonan, Republic of Korea \\ ${ }^{9}$ Department of Psychiatry, Pusan National University Hospital, Busan, Republic of Korea \\ ${ }^{10}$ Department of Social Welfare, College of Social Sciences, Sungkyunkwan University, Seoul, Republic of Korea
}

Objective This study aimed to develop a brief self-report measure of depressive and anxiety symptoms in victims of sexual violence. Methods The sample, which consisted of 215 victims and 255 healthy controls, was recruited between December 2016 and November 2018 from eight Sunflower Centers. Eligible items were selected from existing scales of depression (CES-DC and CES-D) and anxiety (SAI-C and BAI) symptoms by item-total correlation coefficients and item response theory (IRT) analysis. Internal consistency coefficients were computed and the receiver operating characteristics curve was inspected to assess the validity of the brief scale and determine optimal cutoff scores.

Results The brief scales showed high internal consistency across all age groups. The optimal cutoff score of brief depression scale was 1.5 for children, 2.5 for adolescents, and 2.5 for the adults. That of brief anxiety scale was $8.5,6.5$, and 3.5, respectively.

Conclusion The results underscore the need for age-appropriate screening measures of depressive and anxiety symptoms in victims of sexual violence.

Psychiatry Investig 2021;18(2):172-178

Key Words Sexual violence victim, Brief scale, Item response theory, Receiver operating characteristics.

\section{INTRODUCTION}

Sexual violence refers to unwanted sexual acts (e.g., harassment, rape) exhibited toward a nonconsenting individual. It is one of the most vicious crimes, and it can have a wide range of effects on the victim. ${ }^{1}$ Crimes involving domestic sexual violence have increased over the past decade because, as recently covered by the media, there has been an increase in online sex-

Received: October 21, 2020 Revised: December 9, 2020

Accepted: December 12, 2020

$\triangle$ Correspondence: Jae-Won Kim, MD, PhD

Division of Child and Adolescent Psychiatry, Department of Psychiatry \& Behavioral Sciences, Seoul National University College of Medicine, 103 Daehak-ro, Jongno-gu, Seoul 03080, Republic of Korea

Tel: +82-2-2072-3648, Fax: +82-2-747-2471, E-mail: kimjw412@snu.ac.kr

(c) This is an Open Access article distributed under the terms of the Creative Commons Attribution Non-Commercial License (https://creativecommons.org/licenses/by$\mathrm{nc} / 4.0$ ) which permits unrestricted non-commercial use, distribution, and reproduction in any medium, provided the original work is properly cited. ual violence on platforms that are mainly used by adolescents. ${ }^{2}$ Many psychiatric symptoms can emerge as a result of violence. ${ }^{3}$ Campbell et al. ${ }^{4}$ conducted a study among victims of violence and found that the prevalence of posttraumatic stress disorder, depressive disorder, anxiety disorder, and suicidal ideation was $17-65 \%, 13-51 \%, 12-40 \%$, and $23-44 \%$, respectively. In particular, sexual violence against children and adolescents increases their risk of developing behavioral problems, including inappropriate sexual behaviors and psychiatric symptoms such as depression, anger, and anxiety. ${ }^{5}$ When they grow older, they may experience problems such as substance use, suicide attempts, and family problems. Further, they are at an increased risk of being re-exposed to sexual violence or becoming a sexual offender. ${ }^{6}$ Therefore, early interventions, including psychological symptom assessments and close follow-up protocols, are required. ${ }^{7}$ 
It is difficult to assess a wide range of psychiatric symptoms in a community setting. There is no specialized questionnaire for assessing depressive and anxiety symptoms of sexual violence victims. Moreover, issues related to copyright infringement and scale reliability are also relevant problems. ${ }^{8,9}$ In addition, it is difficult to use these scales in real-life situations, because such patients tend to first seek emergency medical services rather than mental health services. ${ }^{10}$ Further, it is not easy to ask several questions about mental health problems in an emergency medical environment. ${ }^{11}$ It can be burdensome and difficult to ask various questions under these circumstances and assess the underlying problems appropriately. Indeed, victims often find it difficult to express their psychological symptoms because of guilt, fear of criticism, remorse, and feelings of shame. ${ }^{12}$ Despite the need for a brief assessment that can assess depression and anxiety in sexual assault victims, no past study has focused on this issue. ${ }^{13,14}$ Therefore, this study aimed to develop a brief self-report measure of depression and anxiety symptoms in sexual violence victims that can be used in community settings.

\section{METHODS}

\section{Study design and participants}

This study was conducted among women who had experienced sexual violence during the past 3 months. Between December 2016 and November 2018, participants were recruited from eight Sunflower Centers located across seven provinces. The Sunflower Center is a sexual assault center that provides multidisciplinary support, including counseling, medical, investigation and legal support for victims of sexual assault and family violence. Eligible women who visited the center were informed about the study, and written informed consent was obtained from them. Control participants were recruited through online posts and local advertisements. This study was approved by the Institutional Review Board (IRB) for Human Subjects of Seoul National University Hospital (IRB No. 1506-073-680).

Initially, 470 individuals ( 215 victims) were recruited. Those whose questionnaires contained missing responses were excluded. Thus, the responses of 459 individuals (210 victims) were included in the final analysis. The characteristics (number of participants and average age) of the participating children, adolescents, and adults were as follows: children $=34$ victims (age: mean $=9.4, \mathrm{SD}=2.04$, range $=5-13$ ) and 33 controls (age: mean $=8.3, \mathrm{SD}=2.0$, range $=5-12$ ); adolescents $=57$ victims (age: mean $=14.9, \mathrm{SD}=1.7$, range $=5-12$ ) and 77 controls (age: mean $=$ $14.5, \mathrm{SD}=1.0$, range $=13-18$ ); and adults $=118$ victims (age: mean $=23.6, \mathrm{SD}=5.8$, range $=18-48$ ) and 139 controls (age: mean $=24.9, \mathrm{SD}=8.0$, range $=18-58$ ).

\section{Measures}

Different scales were used to assess the severity of depressive and anxiety symptoms based on participant age. Depressive symptoms in children and adolescents were assessed using the Center for Epidemiological Studies Depression Scale for Children (CES-DC). Depressive symptoms in adults were assessed using the Center for Epidemiological Studies Depression Scale (CES-D). Anxiety symptoms in children were assessed using the State-Trait Anxiety Inventory for Children (SAI-C), and anxiety symptoms in adolescents and adults were assessed using the Beck Anxiety Inventory (BAI).

The CES-DC is a 20 -item scale, and items are rated on a 4-point Likert scale, which ranges from 0 (not at all) to 3 (a lot). The cutoff score is 15 . Items $4,8,12$, and 16 are reverse scored. ${ }^{15}$ In this study, the Cronbach's $\alpha$ of this scale was 0.94 . The CES$\mathrm{D}$ consists of 20 items that assess depressive symptoms. Items are rated on a 4-point Likert scale that assesses symptom frequency and severity. The scale ranges from 0 to 3 , and the cutoff score is 16 . The Cronbach's $\alpha$ of this scale was 0.90 in this study. ${ }^{16}$ The SAI-C assesses both transient states of anxiety and an anxious disposition. It consists of 20 questions. Items 2, 4, $5,7,9,11,15,16,18$, and 19 are reverse scored. ${ }^{17}$ The cutoff score is 45 . In this study, the Cronbach's a of this scale was 0.95 . The BAI assesses a wide range of physical, emotional, and cognitive symptoms related to anxiety. It consists of 21 items, ${ }^{18}$ which are rated on a 4-point Likert scale that assesses the level of distress caused by symptoms. The rating scale ranges from 0 (not at all) to 3 (severe). The cutoff score is 22 . The Cronbach's $\alpha$ of this scale was 0.95 in this study.

\section{Statistical analysis}

For the purposes of item selection, we conducted item- and factor-level analyses. At the individual-item level, item-total correlation coefficients were computed and item response theory (IRT) analysis was conducted. Item-total correlation coefficients were computed to identify items that were strongly correlated with the total scale score. ${ }^{19}$ With regard to IRT analysis, items with higher difficulty indices identify participants with more symptoms, whereas items with higher discrimination indices distinguish between participants with different levels of symptom severity. We conducted factor analysis with varimax rotation and examined the corrected item-factor correlations that emerged for each factor. Items were selected based on the following previously reported thresholds: item-total and itemfactor correlation coefficient $>0.70,{ }^{20}$ discrimination score $>1.34$ and difficulty score $>0.50$ (IRT), ${ }^{21}$ and factor loading $>0.6{ }^{22}$ Items that met these criteria across three or more analyses were considered, and the scale was finalized after a psychiatrist reviewed the items. The receiver operating characteristic (ROC) analysis was conducted to examine whether the brief scale 
would be useful for diagnostic purposes when compared to existing scales. Next, we identified the cutoff score that differentiated between the victims and control participants. The area under the ROC curve (AUC) was also examined to determine the cutoff scores for the brief rating scale. All analyses were conducted using Statistical Package for the Social Sciences (SPSS) for window, version 23.0 (IBM Corp., Armonk, NY, USA), and p-values $<0.05$ were considered to be significant.

\section{RESULTS}

\section{Item selection}

From CES-DC, items 3, 6, 18, and 20 were selected for inclusion in the measure of depressive symptoms in children, and items 7, 17, and 18 were selected in adolescents. From the CES$\mathrm{D}$, items $1,5,11$, and 17 were selected for inclusion in the measure of depressive symptoms in adults. From the SAI-C, items $4,13,14$, and 20 were selected (i.e., anxiety in children). From the BAI, items $4,8,9,13$, and 17 were selected for inclusion in the measure of anxiety symptoms in adolescents, and items 4 , 5,9 , and 17 were selected for inclusion in the measure of anxiety symptoms in adults. The items that were selected for inclusion in each scale and the corresponding results of statistical analyses are presented in Tables 1 and 2 .

\section{Validation of the brief scale}

The brief scale demonstrated high internal consistency across all age groups. The Cronbach's $\alpha$ of the brief measure of depressive symptoms was 0.81 among children, 0.91 among adoles- cents, and 0.91 among adults. Using ROC analysis, the optimal cutoff score was found to be 1.5 (sensitivity $=0.83$, specificity= 0.88 ) among children, and the AUC value was $0.94(\mathrm{p}<0.001)$. The AUC value was 0.65 ( $\mathrm{p}=0.04)$ for the curve that discriminated between victims and control participants. With regard to the CES-DC, the optimal cutoff score was 2.5 (sensitivity= 0.94 , specificity $=0.86$ ) among adolescents, and the AUC value was $0.96(\mathrm{p}<0.001)$. The AUC value was $0.83(\mathrm{p}<0.001)$ for the curve that discriminated between victims and control participants. Among adults, the optimal cutoff score on the CES-D was 2.5 (sensitivity $=0.94$, specificity $=0.88$ ), and the AUC value was $0.97(p<0.001)$. The AUC value was $0.80(p<0.001)$ for the curve that discriminated between victims and control participants (Figure 1).

The Cronbach's $\alpha$ of the brief measure of anxiety symptoms was 0.75 among children, 0.94 among adolescents, and 0.89 among adults. Using ROC analysis, the optimal cutoff score was found to be 8.5 (sensitivity=1.00, specificity=0.90) among children, and the AUC value was 0.98 ( $\mathrm{p}<0.001)$. The AUC value was $0.64(p=0.06)$ for the curve that distinguished between victims and control participants. With regard to the BAI, the cutoff score was 6.5 (sensitivity $=0.96$, specificity $=0.94$ ) among adolescents, and the AUC value was $0.99(\mathrm{p}<0.001)$. For the curve that differentiated between victims and control participants, the AUC value was $0.74(\mathrm{p}<0.001)$. Among adults, the cutoff score (i.e., for the BAI) was 3.5 (sensitivity $=0.94$, specificity=0.91), and the AUC value was $0.99(\mathrm{p}<0.001)$. The AUC value was 0.86 for the curve that differentiated between the two groups $(\mathrm{p}<0.001)$ (Figure 2).

Table 1. Items selected from measures of depressive symptoms in children (CES-DC), adolescents (CES-DC), and adults (CES-D)

\begin{tabular}{|c|c|c|c|c|c|c|c|}
\hline & & & $\begin{array}{l}\text { Item-total } \\
\text { correlation }\end{array}$ & $\begin{array}{l}\text { Discrimination } \\
\quad(\mathrm{SE})\end{array}$ & $\begin{array}{l}\text { Difficulty } \\
\text { (SE) }\end{array}$ & $\begin{array}{l}\text { Factor } \\
\text { loading }\end{array}$ & $\begin{array}{l}\text { Corrected } \\
\text { item-factor } \\
\text { correlation }\end{array}$ \\
\hline \multirow[t]{4}{*}{ Children } & 3 & $\begin{array}{l}\text { I wasn't able to feel happy, even when my family or } \\
\text { friends tried to help me feel better }\end{array}$ & 0.77 & & $2.42(0.64)$ & 0.88 & 0.88 \\
\hline & 6 & I felt down and unhappy & 0.73 & & $1.43(0.37)$ & 0.68 & 0.73 \\
\hline & 18 & I felt sad & 0.77 & & $1.96(0.48)$ & 0.81 & 0.80 \\
\hline & 20 & It was hard for me to get started on things I had to do & 0.72 & & $1.66(0.41)$ & 0.77 & 0.77 \\
\hline \multirow[t]{3}{*}{ Adolescents } & 7 & I felt like I was too tired to do things. & 0.73 & & $-0.66(0.25)$ & 0.75 & 0.77 \\
\hline & 17 & I felt like crying & 0.78 & & $-0.74(0.25)$ & 0.88 & 0.87 \\
\hline & 18 & I felt sad & 0.82 & & $-0.51(0.25)$ & 0.83 & 0.88 \\
\hline \multirow[t]{4}{*}{ Adults } & 1 & I was bothered by things that usually don't bother me & 0.89 & $41.71(331,136.80)$ & $-0.69(69.33)$ & 0.85 & 0.71 \\
\hline & 5 & I had trouble focusing on what I was doing & 0.91 & $48.35(\mathrm{n} / \mathrm{a})$ & $-0.70(\mathrm{n} / \mathrm{a})$ & 0.89 & 0.75 \\
\hline & 11 & I experienced restless sleep & 0.90 & $52.59(\mathrm{n} / \mathrm{a})$ & $-0.71(\mathrm{n} / \mathrm{a})$ & 0.89 & 0.74 \\
\hline & 17 & I had crying spells & 0.87 & $4.70(1.13)$ & $-0.70(0.11)$ & 0.85 & 0.72 \\
\hline
\end{tabular}

CES-DC: Center for Epidemiological Studies Depression Scale for Children, CES-D: Center for Epidemiological Studies Depression Scale 
Table 2. Items selected from measures of anxiety symptoms in children (SAI-C), adolescents (BAI), and adults (BAI)

\begin{tabular}{|c|c|c|c|c|c|c|c|}
\hline & & & $\begin{array}{l}\text { Item-total } \\
\text { correlation }\end{array}$ & $\begin{array}{l}\text { Discrimination } \\
(\mathrm{SE})\end{array}$ & $\begin{array}{l}\text { Difficulty } \\
\text { (SE) }\end{array}$ & $\begin{array}{l}\text { Factor } \\
\text { loading }\end{array}$ & $\begin{array}{l}\text { Corrected } \\
\text { item-factor } \\
\text { correlation }\end{array}$ \\
\hline \multirow[t]{4}{*}{ Children } & 4 & I feel nervous & 0.71 & & $-1.18(0.31)$ & 0.87 & 0.86 \\
\hline & 13 & I feel not sure & 0.85 & & $-0.22(0.12)$ & 0.83 & 0.89 \\
\hline & 14 & I feel not good & 0.86 & & $-0.30(0.13)$ & 0.83 & 0.89 \\
\hline & 20 & I feel not cheerful & 0.78 & & $-0.22(0.12)$ & 0.81 & 0.82 \\
\hline \multirow[t]{5}{*}{ Adolescents } & 4 & Unable to relax & 0.82 & $3.00(0.88)$ & $0.33(0.14)$ & 0.75 & 0.83 \\
\hline & 8 & Unsteady & 0.83 & $29.74(15239.91)$ & $-0.07(36.15)$ & 0.72 & 0.81 \\
\hline & 9 & Terrified or afraid & 0.75 & $4.22(1.21)$ & $0.16(0.13)$ & 0.88 & 0.83 \\
\hline & 13 & Shaky/unsteady & 0.82 & $2.54(1.07)$ & $0.78(0.19)$ & 0.65 & 0.77 \\
\hline & 17 & Scared & 0.84 & $23.03(552.9)$ & $0.62(1.52)$ & 0.76 & 0.85 \\
\hline \multirow[t]{4}{*}{ Adults } & 5 & Fear of the worst happening & 0.79 & 20.53 (n/a) & 0.64 & 0.83 & 0.82 \\
\hline & 9 & Terrified or afraid & 0.79 & $5.50(1.55)$ & 0.59 & 0.85 & 0.84 \\
\hline & 17 & Scared & 0.8 & $2.60(1.93)$ & 1.43 & 0.69 & 0.76 \\
\hline & 19 & Faint/lightheaded & 0.7 & $2.17(0.89)$ & 1.68 & 0.7 & 0.71 \\
\hline
\end{tabular}

SAI-C: State-Trait Anxiety Inventory for Children, BAI: Beck Anxiety Inventory
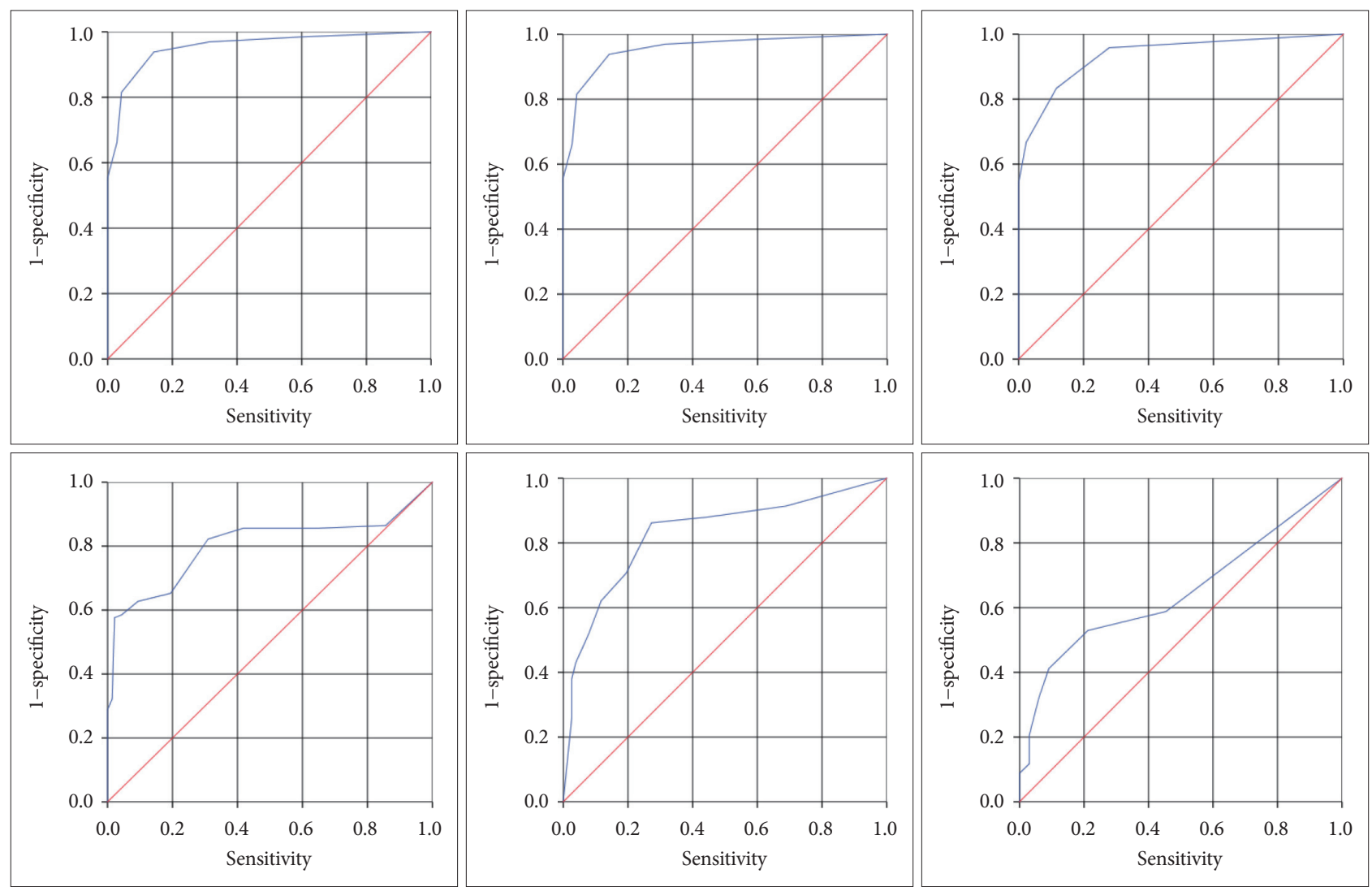

Figure 1. ROC curves for the CES-D and CES-DC. Adults (left), adolescents (middle), and children (right). Comparisons between the original scale and brief version (first row); comparisons between victims and control participants (second row). ROC: receiver operating characteristics, CES-D: Center for Epidemiological Studies Depression Scale, CES-DC: Center for Epidemiological Studies Depression Scale for Children. 

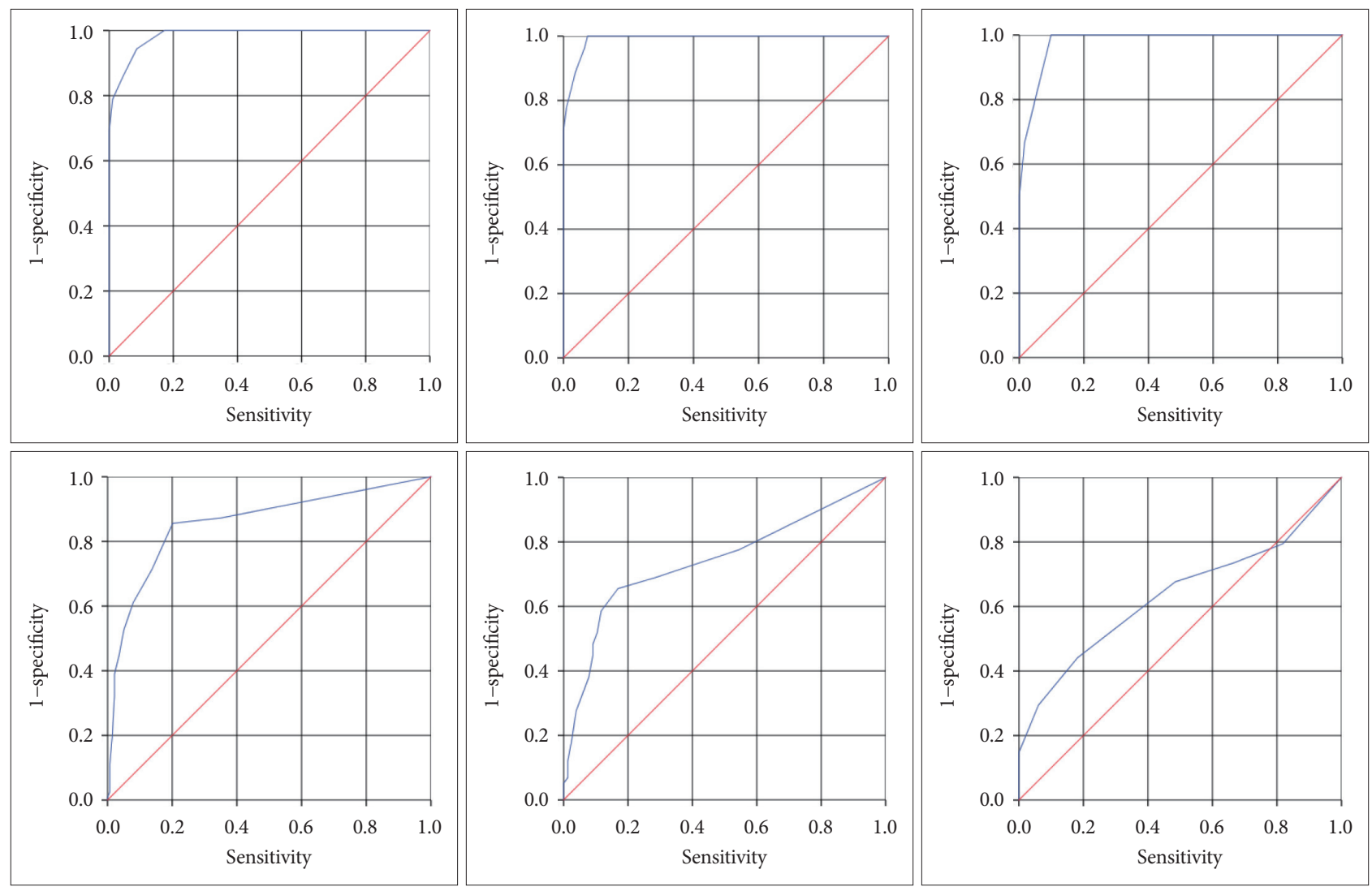

Figure 2. ROC curves for the brief BAI and SAI-C. Adults (left), adolescents (middle), and children (right). Comparisons between the original scale and brief version (first row); comparisons between victims and control participants (second row). ROC: receiver operating characteristics, BAI: Beck Anxiety Inventory, SAI-C: State-Trait Anxiety Inventory for Children.

\section{DISCUSSION}

In this study, brief age-appropriate measures of depressive and anxiety symptoms in children, adolescents, and adults were developed. These scales demonstrated strong internal consistency and yielded acceptable AUC values. Therefore, they can be used to assess depressive and anxiety symptoms based on the suggested cutoff scores for each group.

Different items were included in the measures developed for each age group. This will enhance the effectiveness of evaluations and facilitate early interventions for depressive and anxiety symptoms based on victim's age. The measures of depressive symptoms in children and adolescents included items that assessed mood and lethargy, whereas the corresponding scale for adults also included items that assessed decreased concentration and insomnia. Also, different items were included in the brief measure of anxiety symptoms based on respondent age. The scale developed for children included items that assessed irritability, dysphoric mood, and decreased self-confidence, whereas the corresponding scale for adolescents included items that assessed irritability, fear, and physical symptoms. With regard to adults, items that assessed fear, catastrophic thinking, and physical symptoms were included.
Items that assessed sleep problems were included in the measure of depressive symptoms in adults but not the measure of depressive symptoms in children and adolescents. This observation is consistent with past findings. ${ }^{23}$ Second, the item that assessed decreased concentration was included only in the scale that was developed for adults. This can be conceptualized as a symptom that emerges as cognitive functions develop with age. In addition, there was a decrease in confidence in the children's anxiety disorder scale, which was comparable to other groups. This is in line with previous studies showing that the negative emotions appear as a result of decreased self-esteem in girls $10-12$ years. ${ }^{24}$ This feature is characteristic of girls in this developmental stage, who tend to be socially oriented and ascribe greater importance to peer evaluation.

In this study, more physical symptoms were observed among adolescents and adults than among children. This observation can be juxtaposed against past findings, which suggest that younger patients have more physical symptoms as manifestations of anxiety. ${ }^{25}$ Only the brief measure of depressive symptoms in adults included items that assessed catastrophic thinking, which can be conceptualized as a symptom that is influenced by cognitive development. This partially explains why cognitivebehavioral therapy is more effective among adults than among 
children and adolescents. ${ }^{26}$

In terms of cut-off score measured in the short version scales, the cut-off score of anxiety scale for younger subjects was higher than that for older subjects while depression scale showed a relatively reliable range of cut-off score. One possible explanation for decrease of the anxiety score along with age would be developmental change in cognitive ability. It is possible that younger subjects could not develop adequate coping strategy for anxiety because of their limited cognitive function. ${ }^{27}$ In a previous study, older subjects could use positive self-talk such as "I can take this" better than youngers. Also, the number of coping strategies subjects could use increased with age. ${ }^{28} \mathrm{On}$ the other hand, the cut-off score for anxiety scale was higher than that of the depression scale in the children and adolescents. It is possible that young population manifest many fears and anxieties as part of normal development. ${ }^{29}$ One limitation of this study is that we did not examine the impact of different types of sexual violence. Future studies should examine age differences in depressive and anxiety symptoms according to types of sexual violence. Another limitation of this study is that we used limited only for the female. Response to traumatic events could be varied by gender difference, which should be examined in further studies. This study is the first to have used a large sample of sexual violence victims to validate a brief version of commonly used depression and anxiety scale. The short version scale developed in this study will facilitate prompt and efficient evaluations of depression and anxiety symptoms in victims in community settings.

\section{Acknowledgments}

This research was funded by Korea Mental Health Technology R\&D Project (ID: HM15C1107).

We cooperated with eight Sunflower Centers: Seoul, Gwangju (Child), Gwangju (Crisis), Northwestern Gyeonggi, Gyeongnam, Busan, Jeonbuk, Chungnam.

\section{Conflicts of Interest}

The authors have no potential conflicts of interest to disclose.

\section{Author Contributions}

Conceptualization: Jae-Won Kim. Data curation: Dajung Ji. Formal analysis: Dajung Ji. Funding acquisition: Jae-Won Kim, Kihyun Kim. Investigation: Dajung Ji. Methodology: Soohyun Chae, Jae-Won Kim. Project administration: Dajung Ji, Jae-Won Choi, Ju-yeon Lee, Minha Hong, Tae-Won Park, Kyoung Min Kim, Sunhwa Lee, Soo Yeon Kim. Resources: Jae-Won Kim. Software: Soohyun Chae. Supervision: Jiyoon Shin, JaeWon Choi, Ju-yeon lee, Minha Hong, Tae-Won Park, Kyoung Min Kim, Sunhwa Lee, Soo Yeon Kim, Jae-Won Kim, Kihyun Kim. Validation: Soohyun Chae. Visualization: Soohyun Chae. Writing-original draft: Soohyun Chae, Jiyoon Shin. Writing_review \& editing: Soohyun Chae, Jiyoon Shin, Jae-Won Kim.

\section{ORCID iDs}

Soohyun Chae Jiyoon Shin

Dajung Ji https://orcid.org/0000-0001-8090-5886 https://orcid.org/0000-0003-0510-993X https://orcid.org/0000-0002-8623-6879
Jae-Won Choi

Ju-Yeon Lee

Minha Hong

Tae-Won Park

Kyoung Min Kim

Sunhwa Lee

Soo Yeon Kim

Kihyun Kim

Jae-Won Kim https://orcid.org/0000-0002-4516-1954 https://orcid.org/0000-0003-0653-7223 https://orcid.org/0000-0003-4924-1107 https://orcid.org/0000-0001-5980-0756 https://orcid.org/0000-0003-0577-0701 https://orcid.org/0000-0002-2361-1301 https://orcid.org/0000-0002-4056-800X https://orcid.org/0000-0001-7193-3842 https://orcid.org/0000-0001-8821-6225

\section{REFERENCES}

1. Basile KC, Smith SG, Breiding M, Black MC, Mahendra RR. Sexual violence surveillance: uniform definitions and recommended data elements. Version 2.0. 2014.

2. Chang D, Kim S. A Study on the Punishment and Control of Online Sexual Violence Crime. In: Hahn I, Editor. Korean Institute of Criminology Research Series. Seoul: Korean Institute of Criminology; 2018, p.1-457.

3. Dworkin ER, Menon SV, Bystrynski J, Allen NE. Sexual assault victimization and psychopathology: a review and meta-analysis. Clin Psychol Rev 2017;56:65-81.

4. Campbell R, Dworkin E, Cabral G. An ecological model of the impact of sexual assault on women's mental health. Trauma Violence Abuse 2009;10:225-246.

5. Cohen JA, Deblinger E, Mannarino AP, Steer RA. A multisite, randomized controlled trial for children with sexual abuse-related PTSD symptoms. J Am Acad Child Adolesc Psychiatry 2004;43:393-402.

6. Murray LK, Nguyen A, Cohen JA. Child sexual abuse. Child Adolesc Psychiatr Clin N Am 2014;23:321-337.

7. Maniglio R. The impact of child sexual abuse on health: a systematic review of reviews. Clin Psychol Rev 2009;29:647-657.

8. Ahmad I, Ali PA, Rehman S, Talpur A, Dhingra K. Intimate partner violence screening in emergency department: a rapid review of the literature. J Clin Nurs 2017;26:3271-3285.

9. Savell S. Child sexual abuse: are health care providers looking the other way? J Forensic Nurs 2005;1:78-82.

10. Diaz A, Peake K. Administration of childhood physical and childhood sexual abuse screens in adolescents and young adults: a literature review. Ann Glob Health 2017;83:718-725.

11. Houry D, Kemball RS, Click LA, Kaslow NJ. Development of a brief mental health screen for intimate partner violence victims in the emergency department. Acad Emerg Med 2007;14:202-209.

12. Vrolijk-Bosschaart TF, Brilleslijper-Kater SN, Benninga MA, Lindauer RJL, Teeuw AH. Clinical practice: recognizing child sexual abuse-what makes it so difficult? Eur J Pediatr 2018;177:1343-1350.

13. Ford-Gilboe M, Wathen CN, Varcoe C, MacMillan HL, Scott-Storey K, Mantler T, et al. Development of a brief measure of intimate partner violence experiences: the Composite Abuse Scale (Revised)-Short Form (CASR-SF). BMJ Open 2016;6:e012824.

14. Lang JM, Connell CM. Development and validation of a brief trauma screening measure for children: The Child Trauma Screen. Psychol Trauma 2017;9:390-398.

15. Faulstich ME, Carey MP, Ruggiero L, Enyart P, Gresham F. Assessment of depression in childhood and adolescence: an evaluation of the Center for Epidemiological Studies Depression Scale for Children (CESDC). Am J Psychiatry 1986;143:1024-1027.

16. Roberts RE, Vernon SW. The Center for Epidemiologic Studies Depression Scale: its use in a community sample. Am J Psychiatry 1983; 140:41-46.

17. Spielberger C, Gorsuch RL, Lushene R. STAI manual for the State-Trait Inventory. Palo Alto: Consulting Psychologist; 1970.

18. Ulusoy M, Sahin NH, Erkmen H. The Beck anxiety inventory: psychometric properties. J Cogn Psychother 1998;12:163-172.

19. Primi C, Morsanyi K, Chiesi F, Donati MA, Hamilton J. The develop- 
ment and testing of a new version of the cognitive reflection test applying Item Response Theory (IRT). J Behav Decis Mak 2016;29:453-469.

20. Mukaka M. Statistics corner: a guide to appropriate use of correlation in medical research. Malawi Med J 2012;24:69-71.

21. Baker FB. The Basics of Item Response Theory. College Park: ERIC; 2001.

22. Galinha IC, Pereira CR, Esteves FG. Confirmatory factor analysis and temporal invariance of the Positive and Negative Affect Schedule (PANAS). Psicologia: Reflexão e Crítica 2013;26:671-679.

23. Gillin JC, Duncan WC, Murphy DL, Post RM, Wehr TA, Goodwin FK, et al. Age-related changes in sleep in depressed and normal subjects. Psychiatry Res 1981;4:73-78.

24. Bailey MK, Zauszniewski JA, Heinzer MM, Hemstrom-Krainess AM. Patterns of depressive symptoms in children. J Child Adolesc Psychiatr Nurs 2007;20:86-95.
25. Ogundele MO. Behavioural and emotional disorders in childhood: a brief overview for paediatricians. World J Clin Pediatr 2018;7:9.

26. Barry TJ, Yeung SP, Lau JYF. Meta-analysis of the influence of age on symptom change following cognitive-behavioural treatment for anxiety disorders. J Adolesc 2018;68:232-24.

27. Zimmer-Gembeck MJ, Skinner EA. Review: the development of coping across childhood and adolescence: an integrative review and critique of research. Int J Behav Develop 2010;35:1-17.

28. Brown JM, O’Keeffe J, Sanders SH, Baker B. Developmental changes in children's cognition to stressful and painful situations. J Pediatr Psychol 1986;11:343-357.

29. Muris P, Merckelbach H, Mayer B, Meesters C. Common fears and their relationship to anxiety disorders symptomatology in normal children. Pers Individ Diff 1998;24:575-578. 